\title{
Language Transfer on a Meta-Cognitive Level
}

\author{
Yueyao Wang ${ }^{1, \text { a }}$ \\ ${ }^{1}$ Xi'an University of Architecture and Technology-Caotang, Xi'an 710311, Shaanxi, China. \\ areowang1004@gmail.com
}

Keywords: language transfer; meta-cognitive; Contrastive Analysis Hypothesis; Markedness Differential Hypothesis; Developmental Interdependence Hypothesis

Abstract. This paper aims to discuss and review language transfer on a meta-cognitive level, which includes transfer of language-independent skills such as phonological awareness, structural awareness/decoding, awareness of definitions and functions, good meaning-making strategies/literacy skills, writing strategies and Social/personal skills. Language transfer was defined and discussed in three major theories. An early theory of Contrastive Analysis Hypothesis purposed ways and explanations of language transfer without concerning itself with transfer on a cognitive level. Another early theory, Markedness Differential Hypothesis, identified an important feature "prototypicality" in languages, and purposed an intuitive recognition of prototypicality as a meta-cognitive skill which helps language learners to better transfer skills and information across languages. Cognitive approaches are introduced to better understand language transfer. Developmental Interdependence Hypothesis is among them, which identified skills can be seen as a deeper conceptual and cognitive proficiency that is language-independent and globally transferable across languages (Common Underlying Proficiency). Serval kinds of meta-cognitive transfer are discussed according to fundamental assumptions made in DIH.

\section{Introduction}

Language transfer, also called cross-linguistic influence, refers to a controversial variety of characteristics and influences on second language acquisition [45]. It is the transfer of linguistic features between languages in the speech repertoire of a bilingual or multilingual individual, whether from first to second, second to first or many other relationships [48]. Transfer is thought to play a role in discourse, semantics, syntax, and phonology and phonetics [45], with a heavy research inclination in fields of language-specific phonological processing [31] and tone processing [55] where positive results have yielded from comparative studies.

However, according to the interdependence hypothesis, literacy instruction in a given language develops not only language-specific skills, but also a deeper conceptual and cognitive proficiency that is language-independent and globally transferable across languages [13]. Studies has showed that such language-independent and general-process skills are able to transfer between languages (English and Spanish) in L1-sufficent children in the context of an experimental intervention study where 94 children were randomly assigned to English-only and transitional intervention conditions [30].

The role of language transfer in second language acquisition has been a controversial one [45], theories ranging from early behaviorism believes, contrastive analysis hypothesis and cognitive thinking to theories that concern with inter-language. Transfer on a meta-linguistic and meta-cognitive level, which refers to skills such as verbal and non-verbal IQ, divergent thinking, academic performance, and meta-linguistic awareness [51], was first brought to light by researchers working on linguistic attributes od transfer as a universal skill that only need to be required once by language learners. Meta-cognitive skills also include skills such as "good meaning-making strategies" [41], emergent literacy skills [30], inter-personal skills and originality [51], etc.

\section{Early theories on language transfer}

2.1 Contrastive Analysis Hypothesis (CAH). do [40] described language transfer in a literal sense: "individuals tend to transfer the forms and meanings, and the distributions of forms and meanings 
of their native language and culture to the foreign language and culture", which is the fundamental belief of the CAH. Lado further purposed a famous equation: "difference=difficulty", meaning that any difference between first and second language of a language learner could lead to difficulties in acquisition, thus leading a trend in second language acquisition research to focus mainly on the difference between learners' L1 and L2. Scholars also broke down the concept of "language transfer" into two distinct pieces: positive transfer, which results with a better or faster second language acquisition, and negative transfer, which deters second language acquisition. [57,45]

$\mathrm{CAH}$ is highly influenced by behaviorism and structuralism in both psychology and linguistics that are prevalent in the 1950s and later on [56], with an emphasize on tangible language differences and behaviors related to second language acquisition. Is does not, however, focus on the cognitive or even meta-cognitive aspects of language learning and transfer, such as emergent literacy skills and general phonological awareness (PA). This lack of interest in CAH regarding cognitive aspects of language transfer have always been criticized, among the whether distance between languages should be a linguistic one or a psychological one, whether other factors like markedness, saliency, practical value, and context play a role in language transfer. [58]

2.2 Markedness Differential Hypothesis. The concept of "mark" in a language, or more specifically, in a phoneme, was established by Trubetzkoy [52] and Chomsky [7]. Regarding language transfer, Eckman [21,22] purposed Markedness Differential Hypothesis (MDH) as an attempt to reconcile $\mathrm{CAH}$ with Creative Construction Hypothesis, which focus on creative construction, "the process in which children gradually reconstruct rules for speech they hear, guided by universal innate mechanisms which cause them to formulate certain types of hypothesis about the language system being acquired, until the mismatch between what they are exposed to and what they produce is resolved". [17] "Markedness" is defined by Eckman [21] as: "A phenomenon A in some language is more marked than $\mathrm{B}$ if the presence of $\mathrm{A}$ in a language implies the presence of $\mathrm{B}$; but the presence of B does not imply the presence of A." Ellis [23] summarized how markedness in $\mathrm{L} 1$ and L2 contributes to language transfer in figure 1 below:

\begin{tabular}{llll} 
& L1 & L2 & Interlanguage \\
\hline 1. & Unmarked & Unmarked & Unmarked \\
\hline 2. & Unmarked & Marked & Unmarked \\
\hline 3. & Marked & Unmarked & Unmarked \\
\hline 4. & Marked & Marked & Unmarked
\end{tabular}

Figure 1

Thus arrives the conclusion: language learners tend to transfer attributes in their L1 that are unmarked.

Kellerman [37] approached markedness in language transfer on a cognitive level, purposing an intuitive skill to recognize prototypicality (i.e. markedness) in language learners' L1, which links semantic prototypes with pre-linguistic cognitive schema or image (Coleman \& Kay, 1981). Kellerman [37,38] further purposed such an intuitive recognition of prototypicality helps language learners to determine whether an attribute in their L1 can be transferred and used a Dutch verb "breken" in a sorting test, which showed that language learners' ranks of prototypicality and transferability are correlated. Other studies showed that a language learner with English as L1 sees the word "blue" as "a color", rather than "depression", "jazz" or "pornographic" since "a color" is the prototype of "blue". [39]

As Kellerman suggested, a cognitive approach to MDH could be used to better illustrate and explain the process of language transfer. An intuitive or meta-cognitive awareness of the markedness may lie latent in a language learner's conscious, yet it still compels him to recognize the transferability of a L1 attribute. 


\section{A cognitive approach: Developmental Interdependence Hypothesis}

Cognitive approaches are purposed to better illustrate and explain the process of language transfer on a meta-cognitive level and to show how cognitive process and cognitive strategies are used in language transfer, seeing language acquisition as a part of fundamental cognitive process. An early cognitive approach was introduced by Schachter [47], who stated while analyzing an error in early theories that language transfer is a constraint in the process of language acquisition, that is, all knowledge acquired prior to second language acquisition hinders such acquisition.

Bates \& MacWhinney [2] introduced the Competition Model, which rejects a linguistic faculty in human brain and communication results from mapping of two linguistic levels: the functional level and the formal level. This model has led a series of studies' appearance concerning "L1 influence on L2 production, especially on L2 writing" [33], the cues in L1 and L2 and "language conflict" (which is an attempt to explain how conflicts in a learner's L1 contribute to second language acquisition). [24,34] Guo \& Liu [33] offered a cognitive framework for explaining L1 influence on L2 learner's thinking operations during L2 production using a method called TA (Think Aloud) to record participants' thinking process while writing in a second language (i.e. English). By asking 50 students at different educational levels (high school and college) to write in both L1 (Chinese) and L2 (English) according to a picture, they were able to correlate the thinking operations in L1 to those in L2, leading them to conclude that "L1 influence on L2 production is largely covert; it lies in the high level cognitive operations in language production." They also purposed three aspects that can be seen as meta-cognitive skills of L1 effect on L2 production: "L1's service as intermediary language in logic (meaning) reasoning processing, in the formal monitoring in target language output, and in mutual retrieval of the world conception and the target language."

Cummins [51] introduced the developmental Interdependence Hypothesis (DIH) as an attempt to explain the development of language and linguistic skills of language-minority children, and found that cognitive and personality characteristics contribute as much to the development of L2 academic proficiency as does length of residency [14] and those skills can be seen as a deeper conceptual and cognitive proficiency that is language-independent and globally transferable across languages [25]. He illustrated that in immersion programs, language-minority children's proficiency in L1 can predict their performance and competence in L2. More specifically, a developed skill in L1 can predict a competence in the same skill in language learner's L2, given enough exposure to L2. Cummins [13] also purposed a Common Underlying Proficiency (CUP) as a perspective on transfer, which was used by researchers [30] to refer to language-independent processes that mirrors meta-cognitive skills in language transfer. CUP is a fundamental assumption of DIH: aspects of a language that is not language-specific (e.g., pronunciation and specific vocabulary) which are cognitive or literacy-related can transfer across languages.

3.1 Negative results in meta-cognitive language transfer. Reviews on negative influence from language transfer are available [46,51]. Although they focus mainly on linguistic attributes of language transfer, with studies that had serious methodological flaws, these reviews and studies have reflected a deterrence of second language acquisition when language learners perform in an intelligence or academic test.

Skutnabb-Kangas \& Toukomaa [50] reported that competence in both languages of children of Finnish migrant in Sweden were considerably below average level among their peers. The extent to which their L1 had been developed before the exposure of L2 correlates with their skills in L2. Specifically, children who migrated at age 10 perform a level of Finish close to their Finnish peers and that of Swedish with their Swedish peers, while children who migrated at age 8 were more likely to perform poorly on both languages. This finding suggests that minority children's L1 has functional significance in the development of their L2. It could be argued that when meta-cognitive skills such as literacy skills are yet to be developed in children's L1, they cannot be transferred to L2.

Other studies have yielded similar results, where bilingual children who were instructed in their L2 showed a considerate lower level of verbal, academic, vocabulary and arithmetic skills than 
average in both L1 and L2. [3,43,53] However, the study done by Macnamara [43] has been criticized by Cummins [11] on the ground of testing language minority children on arithmetic questions in their weaker language (Irish).

\subsection{Positive results in meta-cognitive language transfer}

3.2.1 Phonological awareness (PA). PA develops to represent children's spoken language, includes awareness of phonological units such as words, syllables, onset-rimes, and phonemes [18]. PA can be a specific-language-independent skill when there is a large degree of overlap of sounds across languages [15]. Goodrich, Lonigan \& Farver [30] argued that language minority children who can detect and manipulate sounds in one of their languages should also be able to do so in their other languages.

Goodrich, Lonigan \& Farver's study [30] showed that children with higher initial elision skills in their L1 benefitted more from a L2 intervention and showed better PA regards to both their L1 and L2 than children with lower initial skills. They also argued that the results for PA outcomes support only language-independent transfer which is on a meta-cognitive level (i.e., transfer due to a CUP). In alphabetic languages, a large volume of research has showed that children's PA and the skills to process phonemes in L1 significantly predict such skills in their L2 [8,10,20]. In non-alphabetic languages such as Chinese, Gottardo, Yan, Siegel \& Wade-Woolley [31] showed that Chinese Phonological processing as measured by a rhyme detection task can be a statistical predictor of English reading with 65 children whose L1 was Chinese. A similar study has revealed correlation between Chinese onset matching skills and such skills in English, Pinyin reading in Chinese and pseudo word reading [56].

These studies together seem to imply that PA is a language-independent meta-cognitive skill that can be transferred from language learner's stronger language to their L2, even across their languages. Durgunoğlu [18] also pointed out that children's PA in L2 can be assessed even when their L2 oral vocabulary is not fully developed.

3.2.2 Structural awareness and decoding. Structural awareness is crucial in word recognition and spelling performance, children use similar strategies in decoding both their L1 and L2, which may be the reason that instance of negative transfer occur often in such practices. [27] However, positive correlations have been yielded among word recognition and spelling tasks across languages from a large number of studies. [20] L1 decoding skills also predicted L2 competency, which consists of grammar, vocabulary, and reading comprehension [44]. Geva [28] hypotheses that word recognition and spelling follow very similar developmental paths for English as a second language students and English as a first language students. Durgunoğlu [18] thus reached to a conclusion: Language learners who show an awareness of recurring statistical patterns in their home language may be more sensitive to that information in their L 2 as well, given that their L1 and L2 being both alphabetic or non-alphabetic languages.

3.2.3 Awareness of definitions and functions. Children have a meta-cognitive insight of definitions and concepts of the world around them, with a functional awareness of such definitions and concepts, which helps them decode references and metaphors. Studies has showed that awareness of definitions and functions can transfer across language learners' L1 and L2, resulting in a positive outcome. Durgunoğlu [19] compared the formal definition quality of 26 Spanish-English language learners, and found that the quality of formal definition strongly predicts the quality of formal definition in the other language. Verhoeven \& Aarts [54] found that once a language learner noticed the functions and conventions in one language, they tend to apply this knowledge in their other language.

Attributes in language that is closely related to definitions and functions such as reference and metaphors are believed to be transferrable across languages. Cummins [12] used the Meaning and Reference with bilingual children, and found that bilingual children are more vigilant to "incorrect" meaning of words than unilingual children. This finding may substantiate that children who with more than one language display a clearer awareness toward meaning of a word. Johnson [36] showed that metaphor interpretation was most strongly related to meta-cognitive and developmental 
variables (i.e., nonverbal mental capacity and verbal-conceptual repertoire) that are interdependent across languages. Scholars purposed that these results may came from a better cognitive control and conceptual knowledge of bilingual children resulted from their early experience of the arbitrary connection between words and referents, this knowledge maybe developed within one language, but it becomes detached from the word that stands for it. [4,35]

3.2.4 Good meaning-making strategies and literacy skills. A good reader uses good meaning-making strategies such as monitoring their comprehension, constructing a sensible picture and relating the new information to existing background knowledge to create a rich mental representation of their reading material. [18,41] Langer et al. [41] have summarized that we can expect a student with good meaning-making strategies in one language to use those strategies in their L2 based on evidence from their study. Good meaning-making strategies that contributes to a language learner's reading competency can be also interpreted as literacy skills to reading materials. Gebauer, Zaunbauer \& Möller [25] demonstrated that reading comprehension and fluency were correlated across languages within the same constructs, showing literacy skills necessary for successful reading can be transferred to L2 from L1, and they also can be acquired in an L2 context and transferred to L2. Goodrich, Lonigan \& Farver [30] pointed out, the language-independent general-process (which is based on a CUP) part of literacy skills can be transferred across language learners' L1 and L2.

3.2.5 Writing strategies and process. Writing strategies and conventions are expected to transfer across languages since they are direct results of the author's thinking process. Durgunoğlu, et al. [19] reported that in a study with Spanish-English speakers, when asked to write an article according to different pictures, the content of students' English and Spanish stories showed a significate correlation, reflecting the attention, process and strategies used in writing in both languages are similar. As mentioned before, Guo \& Liu [33] approached writing production and strategies though the mental process a student ministered while writing, leading them to believe that the high level cognitive operations in language production is responsible for both L1 and L2 writing process and can be transferred to L2 from language learners' L1. These studies imply that a higher functioning exists as a meta-cognitive skill which directs students' thinking process and thus writing process.

3.2.6 Social and personal skills. Social and communitive skills such as sensitivity to feedback cues may help language learners to better understand others, which could in turn help them achieve to a better L2 level. Several findings suggest that bilinguals may be more sensitive to interpersonal and communicational feedbacks such as facial expressions [1] in both their languages and more adept at certain kinds of communication tasks. [26]

Personal attributes such as intellectual development, originality and divergent thinking can be seen as deep and meta-cognitive skills that are latent influences during the process of language transfer. A large volume of studies has demonstrated verbal and non-verbal intelligence and concept formation in L1 contribute to same attributes in L2 when measured in L1 and L2, respectively $[42,46]$. Cummins \& Gulutsan [16] reported a significant difference between bilingual and unilingual students on a verbal originality test, a finding that was supported by many scholars [49], suggesting that originality developed in both languages can transfer across a language learner's L1 and L2. All of these results suggest a high level of L2 skill is associated with the development of language-independent meta-cognitive skills.

\section{Conclusion and Discussion}

While some scholars mentioned in this paper believe that language transfer on a meta-cognitive level is possible, others are not convinced that such phenomenon exists. As Bialystok and Hakuta [5] stated "It is possible that the representation that bilingual speakers construct for their two languages may include two components-a common representation that is the record of general linguistic knowledge, and separate representations that record language-specific information", cognitive awareness and skills may be a part of language learners' knowledge which does not need to be transferred to the other languages when learning a second language. 
Implications of language transfer on second language acquisition and language training has always been noted by scholars. [30, 43] Language transfer on a meta-cognitive level may prove to be an observable skill in a language learner in future studies to better understand the process of learning. Skills such as PA and social/personal skills which are seen as transferrable may also have further implications in language instruction. Recognition of a similar feature across languages may save much time and energy for instructors and students.

\section{References}

[1] Bain, B. C. (1975). "Toward an integration of Piaget and Vygotsky: Bilingual considerations." Linguistics 13(160): 5-20.

[2] Bates, E., \& MacWhinney, B (1982). "Funetionalist approaches to grammar." E. Wanner \& L.Gleitman (Eds.).

[3] Ben-Zeev, S. (1972). "The influence of bilingualism on cognitive development and cognitive strategy." Child Development 48: 1009-1018.

[4] Bialystok, E. (1986). "Factors in the growth of linguistic awareness." Child Development 57: 498-510.

[5] Bialystok, E., \& Hakuta, K. (1994). In other words: The science and psychology of second-language acquisition, New York: Basic Books.

[6] Blackmore, A., \& Pratt, C. (1997). "Grammatical awareness and reading in grade 1 children." Merrill-Palmer Quarterly 43: 567-590.

[7] Chomsky, N. (1979). Markedness and core grammar.

[8] Cisero, C. A., \& Royer, J. M. (1995). "The development and cross-language transfer of phonological awareness." Contemporary Educational Psychology 20(3): 275-303.

[9] Coleman, L., \& Kay, P. (1981). "Prototype semantics: The English word lie." Language 55: 26-44.

[10] Comeau, L., Cormier, P., Grandmaison, E., \& Lacroix, D. (1999). "A longitudinal study of phonological processing skills in children learning to read in a second language." Journal of Educational Psychology 91(1).

[11] Cummins, J. (1977). "Immersion education in Ireland: a critical review of Macnamara's findings." Working Papers on Bilingualism 13: 121-127.

[12] Cummins, J. (1978). "Bilingualism and the development of metalinguistic awareness." Journal of cross-cultural psychology 9(2): 131-149.

[13] Cummins, J. (1981). The role of primary language development in promoting educational success for language minority students. Los Angeles, CA: California State University, In California State Department of Education, Office of Bilingual Bicultural Education (Ed.).

[14] Cummins, J., Swain, M., Nakajima, K., Handscombe, J., Green, D., \& Tran, C. (1984). Linguistic Interdependence among Japanese and Vietnamese Immigrant Students, InterAmerica Research Associates.

[15] Cummins, J. (1991). "Interdependence of first-and second-language proficiency in bilingual children." Language processing in bilingual children: 70-89.

[16] Cummins, J. G., M. (1974). "Some effects of bilingualism on cognitive functioning." Bilingualism, biculturalism and education 129.

[17] Dulay, H. C., \& Burt, M. K. (1974). "Natural sequences in child second language 
acquisition." Language Learning 24(1): 37-53.

[18] Durgunoğlu, A. Y. (2002). "Cross-linguistic transfer in literacy development and implications for language learners." Annals of Dyslexia 52(1): 189-204.

[19] Durgunoğlu, A. Y., Mir, M., \& Ariño-Marti, S. (2002). The relationships between bilingual children's reading and writing in their two languages. New directions for research in L2 writing, Springer Netherlands: 81-100.

[20] Durgunoğlu, A. Y. V., L. T. (Eds.) (1998). Acquiring literacy in English and Spanish in the United States._Literacy Development in a Multilingual Context: Cross-cultural Perspectives, Mahwah, NJ: Erlbaum and Associates: 135-146.

[21] Eckman, F. R. (1977). "Markedness and the contrastive analysis." Language Learning 27: 315-330.

[22] Eckman, F. R. (1996). "A functional-typological approach to second language acquisition theory." Handbook of second language acquisition: 195-211.

[23] Ellis, R. (1986). Understanding Second Language Acquisition, Oxford: Oxford University Press.

[24] Gass, S. (1984). "A review of interlanguage syntax: Language transfer and language universals." Language Learning 34(2): 115-132.

[25] Gebauer, S. K., Zaunbauer, A. C., \& Möller, J. (2013). "Cross-language transfer in English immersion programs in Germany: Reading comprehension and reading fluency."

Contemporary Educational Psychology 38(1): 64-74.

[26] Genesee, F., Tucker, G. R. \& Lambert, W. E. (1976). "Communication skills of bilingual children." Child Development 46: 1010-1014.

[27] Geva, E., \& Wang, M. (2001). "The development of basic reading skills in children: A cross-language perspective." Annual Review of Applied Linguistics 21: 182-204.

[28] Geva, E. (2001). "Issues in the assessment of reading disabilities in L2 children: Beliefs and research evidence." Dyslexia 6(1): 13-28.

[29] Gleitman, L. R., \& Wanner, E. (Eds.) (1982). Language acquisition: The state of the art, Cambridge University Press.

[30] Goodrich, J. M., Lonigan, C. J. \& Farver, J. M. (2013). "Do Early Literacy Skills in Children's First Language Promote Development of Skills in Their Second Language? An Experimental Evaluation of Transfer." Journal of Educational Psychology 105(2): 414-426.

[31] Gottardo, A., Yan, B., Siegel, L. S. \& Wade-Woolley, L. (2001). "Factors related to English reading performance in children with Chinese as a first language: more evidence of cross-language transfer of phonological processing." Journal of Educational Psychology 93(3): 530-542.

[32] Greenberg, J. H. (1966). Language Universals. Universals of language, The Hague: Mouton.

[33] Guo, C., \& Liu, F. (1997). "A dynamic research into L1 influence on L2 writing." Modern Foreign Languages 4: 30-38.

[34] Harrington, M. (1987). "Processing transfer: Language-specific processing strategies as a source of interlanguage variation." Applied Psycholinguistics 8(04): 351-377.

[35] Hill, J. A., M. (1984). "Schemas, computation, and language acquisition." Human Development 27: 282-296. 
[36] Johnson, J. (1989). "Factors related to cross-language transfer and metaphor interpretation in bilingual children." Applied Psycholinguistics 10(02): 157-177.

[37] Kellerman, E. (1977). "Towards a characterisation of the strategy of transfer in second language learning." Interlanguage Studies Bulletin 2: 58-145.

[38] Kellerman, E. (1978). "Giving learners a break: Native language intuitions as a source of predictions about transferability." Working Papers on Bilingualism Toronto 15: 59-92.

[39] Kellerman, E. (1983). "Now you see it, now you don't." Language transfer in language learning 54(12): 112-134.

[40] Lado, R. (1957). Linguistics Across Cultures: Applied Linguistics for Language Teachers. Ann Arbor, Michigan: University of Michigan, University of Michigan Press ELT.

[41] Langer, J. A., Bartolome, L., Vasquez, O., \& Lucas, T. (1990). " Meaning construction in school literacy tasks: A study of bilingual students." American Educational Research Journal 27: 427-471.

[42] Liedtke, W. W., \& Nelson, L. D. (1968). "Concept formation and bilingualism." Alberta Journal of Educational Research 14(4): 225-232.

[43] Macnamara, J. (1966). Bilingualism and primary education, Edinburgh: Edinburgh University Press.

[44] Meschyan, G., \& Hernandez, A. (2002). "Is native-language decoding skill related to second-language learning?" Journal of Educational Psychology 94(1).

[45] Odlin, T. (1989). Language transfer: cross-linguistic influence in language learning, Cambridge University Press.

[46] Peal, E., \& Lambert, W. E. (1962). "The relation of bilingualism to intelligence." Psychological Monographs: general and applied 76(27).

[47] Schachter, J. (1974). "An Error in Error Analysis." Language Learning 24(2): 205-214.

[48] Scott, J. P., A. (2010). Crosslinguistic Influence in Language and Cognition. London, UK, Taylor \& Francis Ltd.

[49] Scott, S. (1973). The Relation of Divergent Thinking to Bilingualism, Cause Or Effect, McGill University.

[50] Skutnabb-Kangas, T., \& Toukomaa, P. (1976). "Teaching migrant children's mother tongue and learning the language of the host country in the context of the socio-cultural situation of the migrant family." Tampereen yliopiston sosiologian ja sosiaalipsykologian laitos 15.

[51] Swain, M., \& Cummins, J. (1979). "Bilingualism, cognitive functioning and education." Language Teaching 12(01): 4-18.

[52] Trubetzkoy, N. (1931). "Die phonologischen systeme." Travaux du Cercle linguistique de Prague 4: 96-116.

[53] Tsushima, W. T., \& Hogan, T. P. (1975). "Verbal Ability and School Achievement of Bilingual and Monolingual Children of Different Ages." The Journal of Educational Research 68(9): 349-353.

[54] Verhoeven, L., \& Aarts, R. (1998). Attaining functional biliteracy in the Netherlands. A. $Y$. Durgunoğlu \& L. Verhoeven (Eds.), Literacy development in a multilingual context:

Cross-cultural perspectives (pp. 111-133). Mahwah, NJ: Erlbaum and Associates.

[55] Wang, M., Perfetti, C. A. \& Liu, Y. (2005). "Chinese-English biliteracy acquisition: 
cross-language and writing system transfer." Cognition 97(1): 67-88.

[56] Wang, W. (1999). "Review and reflection on the studies of language transfer." Foreign Language Education 20: 6-12.

[57] Weinreich, U. (1953). Languages in Contact: findings and problems, New York, Linguistic Circle of New York.

[58] Zobl, H. (1983). "Markedness and the projection problem." Language Learning 33(3): 293-313. 